\title{
EVALUATION OF BENDING STRENGTH IN FRICTION WELDED ALUMINA/MILD STEEL JOINTS BY APPLYING FACTORIAL TECHNIQUE
}

\author{
N. RAJESH JESUDOSS HYNES* \\ Assistant Professor, Department of Mechanical Engineering, Mepco Schlenk \\ Engineering College, Sivakasi, Tamil Nadu 626005, India \\ findhynes@yahoo.co.in ${ }^{\dagger}$ \\ P. NAGARAJ \\ Professor \& Head, Department of Mechanical Engineering, \\ Mepco Schlenk Engineering College, Sivakasi, Tamil Nadu 626005, India \\ nithyanraj@yahoo.com \\ M. VIVEK PRABHUII \\ year M.E. CAD/CAM PG Student \\ Department of Mechanical Engineering, \\ Mepco Schlenk Engineering College, Sivakasi, Tamil Nadu 626005, India \\ vivekprabhu.mech@gmail.com
}

\begin{abstract}
Joining of metal with ceramics has become significant in many applications, because they combine properties like ductility with high hardness and wear resistance. By friction welding technique, alumina can be joined to mild steel with AA1100 sheet of $1 \mathrm{~mm}$ thickness as interlayer. In the present work, investigation of the effect of friction time on interlayer thickness reduction and bending strength is carried out by factorial design. By using ANOVA, a statistical tool, regression modeling is done. The regression model predicts the bending strength of welded ceramic/metal joints accurately with $\pm 2 \%$ deviation from the experimental values.
\end{abstract}

Keywords: Alumina; Interlayer; Mild steel; Friction Welding.

\section{Introduction}

The excellent elevated temperature strength and resistance to corrosion and wear make ceramic materials highly attractive for use in electronic, aerospace, nuclear and automotive industries ${ }^{[1]}$. Instead of the single piece ceramic component, joining of such materials is often preferred. When a complicated geometry of ceramic components is manufactured, the inherent brittleness associated with the ceramics limits their application in structural applications. Metal/ceramic joints become more important in modern technology, because they combine the properties of metals like ductility and high electrical and thermal conductivity and the properties of ceramics such as high hardness, corrosion and wear resistance ${ }^{[2]}$. Micro structural development on ceramic-metal interfaces plays a critical role in all of these processes ${ }^{[3]}$. The phenomenon of ceramic- 
metal interface formation is not simple and requires an understanding of the thermodynamics, kinetics, and mechanical properties of all of the phases that are present including the interfaces between phases, which also have unique properties and, thus act as independent constituents. The aim of the present paper is to evaluate the bond strength of the Al2O3/mild steel via friction welding by using the statistical tool, ANOVA and a regression model is to be developed for predicting the bending strength of the friction welded joints.

\section{Methods and Materials}

In the experimental work, carried out by Noh et al., (2008) Alumina rods of $10 \mathrm{~mm}$ diameter were prepared through slip casting process. Mild Steel specimens were made as per required dimensions shown in figure $1^{[4]}$. The dissimilar specimens were welded on a continuous drive friction welding machine using AA1100 sheet as interlayer. The joints were prepared on a direct drive friction welding machine modified from an existing lathe. A friction pressure of $20 \mathrm{MPa}$ was applied and forging pressure was maintained at $40 \mathrm{MPa}$, a rotational speed of 900rpm was used, while friction and forging times were varied from 2 to 20s in the experiment by Noh et al., ${ }^{[4]}$. The elemental composition of mild steel, aluminium interlayer and alumina are shown in Table 1.

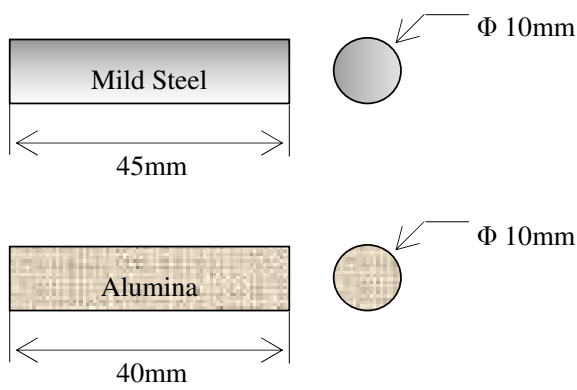

Figure 1 - Geometric structure and dimensions of the Specimens

The successful friction joints were measured for their four point bending strength using Instron model 8501 by Noh et al. Samples were observed under the optical microscope to measure the interlayer thickness and a scanning electron microscope (SEM) were used to evaluate the integrity of the interface and bonding characteristics ${ }^{[4]}$.

Table 1 Chemical composition of steel, aluminium sheet and alumina

\begin{tabular}{cccccccccccc}
\hline & \multicolumn{10}{c}{ Content (wt \%) } \\
Sample & $\mathrm{C}$ & $\mathrm{Si}$ & $\mathrm{P}$ & $\mathrm{Cr}$ & $\mathrm{Mn}$ & $\mathrm{Ni}$ & $\mathrm{O}$ & $\mathrm{Cu}$ & $\mathrm{Al}$ & $\mathrm{Fe}$ & $\mathrm{Bal}$ \\
\hline Steel & 0.30 & 0.22 & 0.02 & 0.12 & 0.78 & 0.10 & - & 0.44 & - & 98 & $<0.01$ \\
Aluminium Sheet & - & 1.0 & - & - & - & - & - & 0.07 & 98.0 & 0.4 & $<0.01$ \\
Alumina & - & - & - & - & - & - & 47.28 & - & 52.71 & - & $<0.01$ \\
\hline
\end{tabular}




\section{Results and Discussions}

It had been reported that alumina and mild steel rods were successfully joined using friction welding technique at constant rotational speed of $900 \mathrm{rpm}$ with $1.0 \mathrm{~mm}$ aluminium interlayer. However, the experiments were also carried out without using aluminium as an interlayer. The joint totally could not be formed (Noh et al., 2005) and the alumina rods experienced cracking and breaking during friction welding process. This indicates the aluminium interlayer as an essential intermediate medium in the formation of a good joint between alumina and mild steel.

Table 2 Tabulation of readings with calculated burn off speed and heat input

\begin{tabular}{ccccc}
\hline $\begin{array}{c}\text { Friction } \\
\text { Time } \\
(\mathrm{s})\end{array}$ & $\begin{array}{c}\text { Interlayer } \\
\text { Thickness } \\
(\mu \mathrm{m})\end{array}$ & $\begin{array}{c}\text { Bending } \\
\text { Strength } \\
(\mathrm{MPa})\end{array}$ & $\begin{array}{c}\text { Burn Off } \\
\text { Speed } \\
(\mu \mathrm{m} / \mathrm{s})\end{array}$ & $\begin{array}{c}\text { Unit Deformation } \\
\text { heat input } \\
(\mathrm{KJ} / \mathrm{s})\end{array}$ \\
\hline 6 & 480 & 105 & 86.7 & 68.03 \\
8 & 440 & 140 & 70 & 54.95 \\
10 & 358 & 145 & 64.2 & 50.40 \\
12 & 343 & 170 & 54.75 & 42.93 \\
14 & 295 & 180 & 50.36 & 39.25 \\
16 & 248 & 200 & 47 & 36.89 \\
18 & 211 & 240 & 43.83 & 34.23 \\
20 & 196 & 245 & 40.2 & 31.56 \\
\hline
\end{tabular}

\subsection{Evaluation of bending strength using heat input}

The unit friction heat input per unit time

$$
Q_{f r i}=2 \pi \mathrm{N} T
$$

The unit deformation heat input per unit time

$$
Q_{\text {for }}=F V_{\delta}
$$

The unit total heat input per unit time

$$
Q_{t o t}=Q_{f r i}+Q_{f o r}
$$

Where F - Thrust $(\mathrm{N}), \mathrm{V}_{\delta}$ - Burn off speed, $\mathrm{Q}_{\text {fri }}-$ Unit frictional heat input per unit time, $\mathrm{Q}_{\text {for }}-$ Unit deformation heat input per unit time, $\mathrm{Q}_{\text {tot }}-$ Unit total heat input per unit time. 


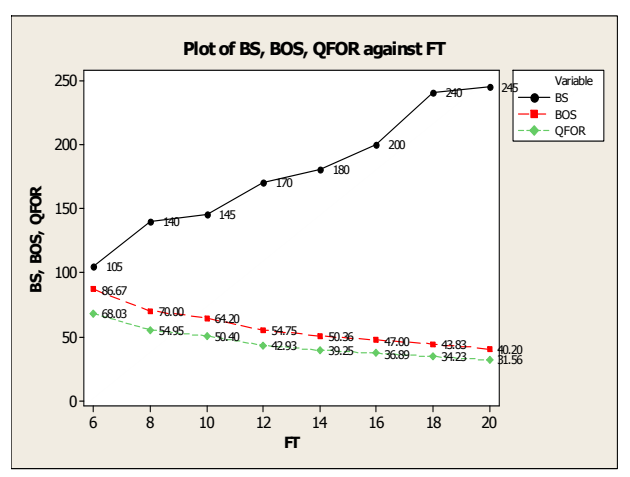

Figure 2

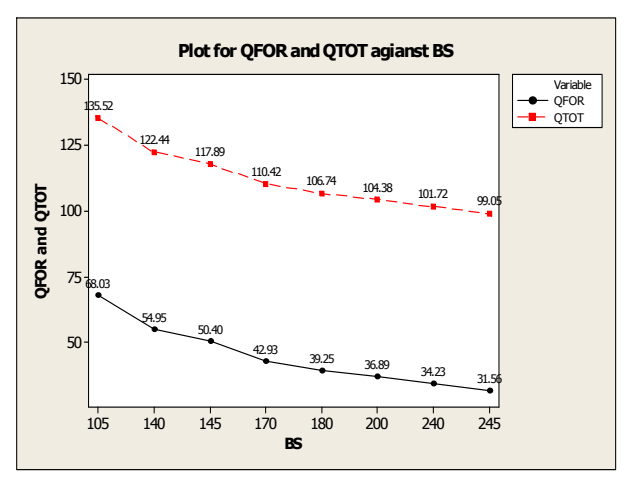

Figure 3

Figure 2 - Plot of BS, BOS and QFOR against FT

Figure 3 - Plot of QFOR and QTOT against BS

Where FT - Friction Time, BS - Bending Strength, BOS - Burn Off Speed, QFOR - Unit deformation heat input per unit time, QTOT - Unit total heat input per unit time.

\section{Regression Analysis}

Regression Analysis generates an equation to describe the statistical relationship between one or more predictors and the response variables to predict new observations. Regression generally uses the ordinary least squares method which derives the equation by minimizing the sum of the squared residuals. P-value for each coefficient tests the null hypothesis that the coefficient is equal to zero (no effect). Therefore, low p-values suggest the predictor is a meaningful addition to your model. The equation predicts new observations given by specified predictor values. The regression coefficient of weld parameters (friction time and interlayer thickness) vs response (bending strength) is given in table 3 .

\subsection{Regression analysis for bending strength}

The regression equation for bending strength is

$$
\mathrm{BS}=-25+12.5 \mathrm{FT}+0.126 \mathrm{IT}
$$

Table 3 Regression coefficients of weld parameters vs Bending Strength

\begin{tabular}{lrrrr}
\hline Predictor & Coef & SE Coef & T & P \\
\hline Constant & -24.8 & 133.7 & -0.19 & 0.860 \\
FT & 12.491 & 4.753 & 2.63 & 0.047 \\
IT & 0.1263 & 0.2249 & 0.56 & 0.599 \\
\hline
\end{tabular}

Where BS - Bending Strength, FT - Friction Time, IT - Interlayer Thickness 


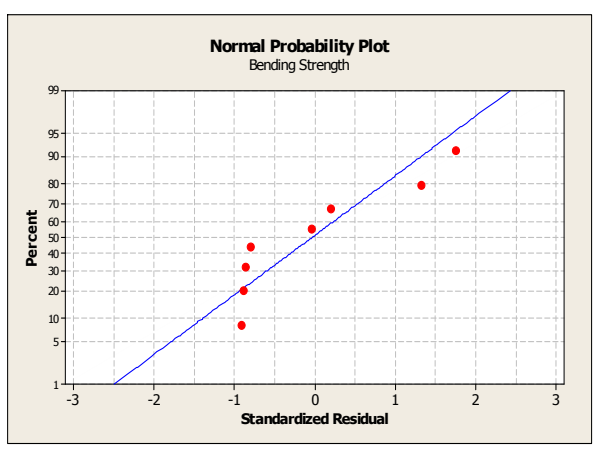

Figure 4

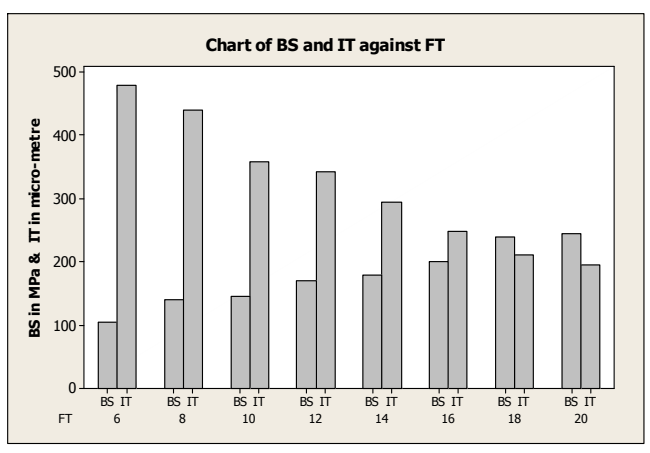

Figure 5

Figure 4 - Normal Plot of Residuals for Bending Strength

Figure 5 - Bar chart for Bending Strength and Interlayer Thickness against Friction Time

\subsection{Analysis of variance (ANOVA)}

ANOVA is a statistical technique used for analyzing the data from experiments. ANOVA compares the response variable means at the different factor levels to evaluate the importance of one or more factors. The experimental data for the response (Bending strength) is analysed using ANOVA to identify the significantly contributing factors. The ANOVA table for bending strength is shown below in Table 4.

Table 4 Analysis of Variance for Bending Strength, using adjusted SS for tests

\begin{tabular}{|c|c|c|c|c|c|c|}
\hline \multicolumn{2}{|c|}{$\begin{array}{l}\text { Analysis of } \\
\text { for Tests }\end{array}$} & Variance & for BS, & using & djus & SS \\
\hline Source & $\mathrm{DF}$ & Seq SS & Adj $S S$ & Adj MS & $\mathrm{F}$ & $\mathrm{P}$ \\
\hline $\mathrm{ET}$ & 1 & 16303.7 & 575.8 & 575.8 & 6.91 & 0.047 \\
\hline IT & 1 & 26.3 & 26.3 & 26.3 & 0.32 & 0.599 \\
\hline Error & 5 & 416.9 & 416.9 & 83.4 & & \\
\hline Total & 7 & 16746.9 & & & & \\
\hline
\end{tabular}

The percentage contribution of factors for bending strength is given in phi chart as shown in Figure 6.

\section{Contribution for BS by FT \& IT}

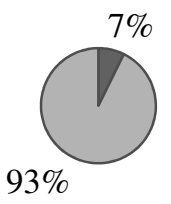

Eriction Time

Figure 6 - Contribution of Friction time \& Interlayer thickness on Bending Strength 


\section{Conclusion}

By applying factorial design and ANOVA on the experimental work ${ }^{[4]}$ of joining of ceramics and mild steel, following conclusions are made.

i. Total heat input per unit time increases with friction time and leads to the increase in bending strength.

ii. Interlayer is necessary for the successful joint of alumina/mild steel. Interlayer contributes around $93 \%$ to the bending strength of the welded joint.

iii. The possibility of intermetallic compound depends on heat input and heat input depends on friction time. Friction time contributes around $7 \%$ to the bending strength.

iv. Regression Equation has been developed to predict the bending strength of ceramic/metal joint with $\pm 2 \%$ deviation.

\section{References}

1. A. Meier, D.A. Javernick, G.R. Edwards, 1999. Ceramic-metalinterfaces and the spreading of reactive liquids. JOM, 44-47.

2. S. Mandal, A.K. Ray, A.K. Ray, 2004. Correlation between themechanical properties and the microstructural behaviour of $\mathrm{Al}_{2} \mathrm{O}_{3^{-}}(\mathrm{Ag}-\mathrm{Cu}-\mathrm{Ti})$ brazed joints. Mater. Sci. Engg. A 383,235244.

3. M.Z. Noh, B.H. Luay, A.A. Zainal, 2005. Effect of friction time onthe strength of aluminasteel bonding through frictionwelding. In: Ahmad, A. (Ed.), Proceeding of BruneiInternational on Engineering and Technology, vol. 4, pp. 91-97.

4. M.Z. Noh, B.H. Luay, A.A. Zainal, 2008. Alumina-mild steel friction welded at lower rotational speed. J. Mater. Process. Technol. 204, 279-283.

5. A.A. Essa, A.S. Bahrani, 1991. The friction joining of ceramics tometals. J. Mater. Process. Technol. 26, 133-140.

6. C. Kohnle, O. Mintchev, D. Brunner, S. Schmauder, 2000. Fracture of metal/ceramic interfaces. Comput. Mater. Sci. 19,261-266.

7. N. O"zdemir, F. Sarsilmaz, A.Hascalik, 2007. Effect of rotationalspeed on the interface properties of friction-welded AISI 304Lto 4340 steel. Mater. Des. 28, 301-307.

8. Z. Lindemann, K. Skalski, W. Wlosinski, J. Zimmerman, 2006. Thermo-mechanical phenomena in the process of friction welding of corundum ceramics and aluminium. Bull. Pol. Ac.: Tech 54(1). 